\title{
PREFERENSI MASYARAKAT DALAM MEMILIH PERUMAHAN DENGAN MENGGUNAKAN METODE FUZZY ANALYTICAL HIERARCHY PROCESS (F-AHP) DI KABUPATEN KARANGANYAR
}

\author{
Muhammad Rizan Adam ${ }^{1}$ ), Setiono. ${ }^{2}$ ), Sugiyarto ${ }^{3}$ ) \\ 1) Mahasiswa Fakultas Teknik, Prodi Teknik Sipil, Universitas Sebelas Maret \\ 2) Pengajar Fakultas Teknik, Prodi Teknik Sipil, Universitas Sebelas Maret \\ 3) Pengajar Fakultas Teknik, Prodi Teknik Sipil, Universitas Sebelas Maret \\ Jl. Ir. Sutami 36A, Kentingan Surakarta 57126; Telp. (0271) 634524, Fax 662118 \\ Email : rizan.adam13@gmail.com
}

\begin{abstract}
The rapid development of the community has triggered an increase in the number of residential needs, especially housing which usually occurs in urban areas. More and more housing needs, make developers begin to develop their projects by offering various facilities that are expected to help and benefit home buyers. Before building housing, of course the developer will study the things that can bring the biggest profit. Thus, the developer will provide various facilities for housing to attract buyers. For this reason, it is necessary to conduct research related to community preferences or preferences in choosing housing that is in accordance with community needs. This study aims to determine the factors that most influence the community in choosing housing. This study uses the Fuz:y Analytical Hierarchy Process (F-AHP) method by filling out questionnaires by the public and processing data using Microsoft Excel 2016. Software results. While the results of the study indicate that the safety and comfort factors get the greatest weighting value and are the factors that most influence the community in choosing housing.
\end{abstract}

Keywords : populations preferences, housing selection, Fuzzy Analytical Hierarchy Process method (F-AHP).

\begin{abstract}
Abstrak
Perkembangan masyarakat yang berlangsung secara pesat memicu bertambahnya jumlah kebutuhan tempat tinggal terutama perumahan yang biasanya terjadi di daerah perkotaan. Semakin banyak kebutuhan akan perumahan, membuat para pengembang (developer) mulai mengembangkan proyek-proyeknya dengan menawarkan berbagai fasilitas yang diharapkan dapat membantu dan menguntungkan para pembeli rumah. Sebelum membangun perumahan, tentu developer akan mengkaji hal-hal yang dapat mendatangkan keuntungan terbesar. Dengan demikian, developer akan menyediakan berbagai fasilitas pada perumahan untuk menarik minat para pembeli. Untuk itu, perlu dilakukan penelitian terkait preferensi atau selera masyarakat dalam memilih perumahan yang sesuai dengan kebutuhan masyarakat. Penelitian ini bertujuan untuk mengetahui faktor yang paling mempengaruhi masyarakat dalam memilih perumahan. Penelitian ini menggunakan metode Furay Analytical Hierarchy Process (F-AHP) dengan pengisian kuisioner oleh masyarakat dan pengolahan data menggunakan program software Microsoft Excel 2016. Sementara hasil penelitian menunjukkan bahwa faktor keamanan dan kenyaman mendapatkan bobot nilai terbesar dan merupakan faktor yang paling mempengaruhi masyarakat dalam memilih perumahan.
\end{abstract}

Kata kunci: preferensi masyarakat, pemilihan perumahan, metode Fuz:y Analytical Hierarchy Process (F-AHP).

\section{PENDAHULUAN}

Kota merupakan suatu konsentrasi masyarakat dalam suatu wilayah geografis yang berkehidupan secara mandiri yang dapat berupa pusat perekonomian, perdagangan, perindustrian, pendidikan, pemerintahan dan lain-lain. Keadaan ini yang mendorong penduduk dari daerah pedesaan untuk berpindah ke kota. Perkembangan suatu kota sangat dipengaruhi oleh jumlah penduduk dan persebarannya. Pertambahan jumlah penduduk yang tiap tahun meningkat akan mengakibatkan peningkatan kebutuhan akan tempat tinggal yang disebut rumah.

Perumahan dan permukiman merupakan salah satu hal yang harus terpenuhi oleh manusia. Rumah tidak hanya berfungsi sebagai tempat hunian, namun juga sebagai wadah aktivitas interaksi manusia. Dalam setiap kegiatan pembangunan, masalah pemilihan lokasi maupun pemanfaatan lahan terbangun harus dipertimbangkan secara cermat dan dipilih secara tepat, agar kegiatan tersebut dapat berlangsung secara produktif dan efisien. Permintaan perumahan pasti akan meningkat dari tahun ke tahun. Pembangunan perumahan perlu ditingkatkan dan dikembangkan secara terencana, terpadu, terarah, dan berkesinambungan. Pada pelaksanaannya perlu mempertimbangkan berbagai aspek sehingga menjadi satu kesatuan fungsional dari wujud tata ruang fisik, kehidupan ekonomi, dan sosial budaya untuk mendukung dan menjamin kelestarian lingkungan hidup dan meningkatkan kualitas kehidupan manusia dalam berkeluarga dan bermasyarakat. Preferensi atau selera adalah salah satu hal yang memepengaruhi pembangunan perumahan di suatu kota. Developer atau pengembang akan menganalisis preferensi masyarakat di suatu kota dalam hal ini adalah konsumen sebelum membangun sebuah perumahan. 
Keberadaan Kabupaten Karanganyar yang merupakan salah satu kota di Provinsi Jawa Tengah yang juga merupakan pusat kegiatan perekonomian, perdagangan, pendidikan, kebudayaan, dan sektor informal lainnya. Dengan kondisi demikian, banyak para pendatang dari daerah sekitar Kabupaten Karanganyar maupun daerah luar yang datang dengan tujuan untuk berdagang, bekerja, belajar, dan lain-lain. Keadaan ini di satu sisi menimbulkan masalah tempat tinggal bagi masyarakat tetapi di sisi lain merupakan peluang bagi kalangan developer atau pengembang untuk menyediakan sarana hunian dengan membangun perumahan-perumahan yang dibutuhkan. Selain itu, pengembang akan memperoleh keuntungan dari usaha yang dijalankan. Untuk mencapai tujuan tersebut, pengembang membuat perencanaan pembangunan yang mempertimbangkan faktor-faktor yang mempengaruhi pembangunan tersebut. Konsumen yang merupakan faktor penentu dari bisnis properti ini sangat menentukan berhasil atau tidaknya sebuah bisnis perumahan. Tolok ukur keberhasilan bisnis perumahan adalah banyaknya rumah yang terjual kepada konsumen. Oleh karena itu, pengembang perlu mengetahui perilaku konsumen dalam memilih rumah (perumahan).

Gejolak perkembangan di bidang properti ini tidak hanya dipengaruhi oleh perbaikan perekonomian tetapi juga minat para konsumen mengikuti perkembangan. Peningkatan jumlah konsumen dari tahun ke tahun membuat para developer menawarkan berbagai alternatif dari mulai harga, lokasi, desain, maupun cara pembayaran. Hal inilah yang menyebabkan konsumen harus pandai-pandai memilih alternatif perumahan mana yang akan mereka ambil yang sesuai dengan kriteria-kriteria yang diinginkan.

\section{LANDASAN TEORI}

\section{Rumah}

Bangunan yang berfungsi sebagai tempat tinggal atau hunian dan sarana pembinaan keluarga. Rumah sebagai tempat membina keluarga, tempat berlindung dari iklim dan tempat menjaga kesehatan keluarga.

\section{Masyarakat (society)}

Kegiatan berhadapan dengan orang-orang dan saling berinteraksi dengan kecenderungan populasi, menggolongkan perilaku, kebiasaan sosial, jabatan, pendudukan, pendapatan, dan pemerintahan.

\section{Perumahan}

Kelompok rumah yang berfungsi sebagai lingkungan tempat tinggal atau lingkungan hunian yang dilengkapi dengan prasarana dan sarana lingkungan

\section{Tujuan Perencanaan Perumahan}

Menurut UU RI No.4 Tahun 1992 tentang Perumahan dan Permukiman, tujuan perencanaan perumahan adalah sebagai berikut :

1. Memenuhi kebutuhan rumah sebagai salah satu kebutuhan dasar manusia, dalam rangka peningkatan dan pemerataan kesejahteraan rakyat.

2. Mewujudkan perumahan dan permukiman yang layak dalam lingkungan yang sehat, aman, serasi dan teratur.

3. Memberi arah pada pertumbuhan wilayah dan persebaran penduduk yang rasional.

4. Menunjang pembangunan di bidang ekonomi, sosial, budaya, dan bidang-bidang lain.

\section{Teori Lokasi Perumahan}

Teori pemilihan lokasi tempat tinggal dicetuskan oleh banyak pakar, baik pakar ekonomi, perencana, dan pakar lainnya. Mereka menjelaskan bahwa pertimbangan rumah tangga dalam memilih lokasi tempat tinggal yang optimal dipengaruhi oleh income, land rent, dan transportation cost. Penulis juga menggunakan bebrapa jurnal dan penelitian terdahulu sehingga diambil beberapa teori :

1. Lust

2. Prayogo Mirhad

3. Goodall

4. Komaruddin

5. Pedoman Teknik Pembangunan Perumahan Sederhana Tidak Bersusun (Departemen PU)

6. Kriteria Teknis Penataan Ruang Kawasan Budidaya (Departemen PU)

7. Mu'ammar Qathafi 


\section{Teori Analytical Hierarchy Process (AHP)}

Menurut Saaty (1994), AHP merupakan pendekatan dasar dalam pengambilan keputusan yang dirancang untuk mengatasi perbedaan antara rasionalitas dan intuitif dalam menentukan keputusan terbaik dari sejumlah alternatif yang dievaluasi sehubungan dengan beberapa kriteria. Proses pembuatan keputusan dilakukan dengan penilaian perbandingan berpasangan sederhana yang kemudian digunakan untuk mengembangkan seluruh prioritas untuk menentukan bobot nilai dari setiap alternatif sehingga dapat ditentukan peringkat/hierarki dari seluruh alternatif yang ada. Penggunaan metode AHP memungkinkan adanya inkonsistensi dalam penilaian dan mampu meningkatkan konsistensi dari alternatif yang ada.

Beberapa tahapan yang perlu dilakukan sebelum melaksanakan analisis pada metode AHP menurut Mardhikawarih (2012) adalah:

1. Menentukan tujuan $A H P$ secara keseluruhan.

2. Menentukan faktor yang berperan dalam pengambilan keputusan.

3. Menentukan kriteria yang perlu dipertimbangkan untuk mencapai tujuan.

4. Menentukan subkriteria yang berada satu tingkat di bawah kriteria.

5. Menentukan alternatif-alternatif untuk mencapai tujuan.

\section{Teori Fuzzy Analytical Herarchy Process (F-AHP)}

F-AHP merupakan salah satu metode perangkingan. F-AHP adalah gabungan dari metode AHP dengan pendekatan konsep furzy. F-AHP menutupi kelemahan yang terdapat pada AHP, yaitu permasalahan terhadap kriteria yang memiliki sifat subjektif lebih banyak. Ketidakpastian bilangan dipresentasikan dengan urutan skala. Untuk menentukan derajat keanggotaan pada F-AHP, digunakan aturan fungsi dalam bentuk bilangan fuz:y segitiga atau Triangular Fuz:y Number (TFN).

Bilangan Triangular Fu₹zy merupakan teori himpunan furzy yang membantu dalam pengukuran yang berhubungan dengan penilaian subjektif manusia memakai bahasa atau linguistik. Inti dari F-AHP terletak pada perbandingan berpasangan yang digambarkan dengan skala rasio yang berhubungan dengan skala furay.

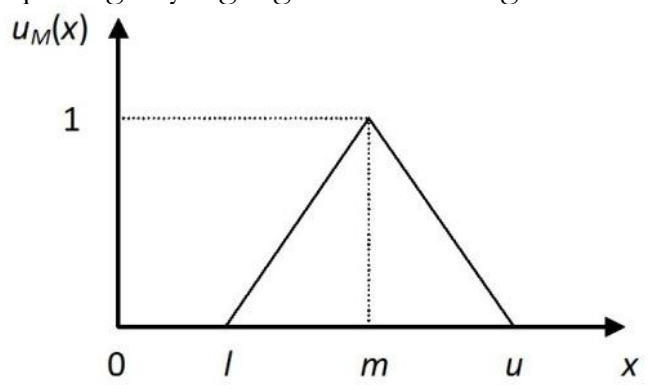

TFN disimbolkan dengan $M=(l, m, u)$, dimana $l \leq m \leq u$ dan $l$ adalah nilai terendah, $m$ adalah nilai tengah, $u$ adalah nilai teratas.

\section{METODE}

Penelitian ini menggunakan metode Fur:y Analytical Hierarchy Process (F-AHP) dan metode deskripsi kualitatif untuk memperjelas permasalahan dalam pemilihan rumah dengan mengidentifikasi faktor-faktor teknis yang berpengaruh dalam pemilihan rumah. Data yang digunakan terdiri dari data primer dan data sekunder. Data primer merupakan data yang berupa data observasi dan angket/ kuesioner. Sedangkan data sekunder yang digunakan berupa data penghuni, jumlah penduduk, topografi, jumlah unit rumah, banyaknya perumahan, dan data lain yang diperlukan.

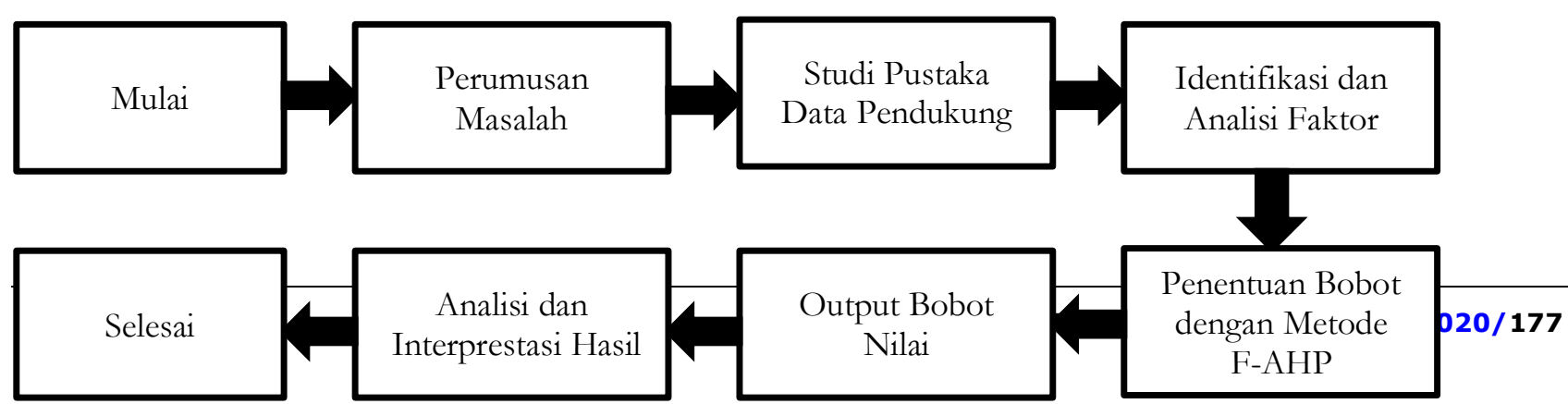




\section{HASIL DAN PEMBAHASAN}

Berdasarkan penelitian dengan melakukan perbandingan antara pembobotan nilai faktor dan subfaktor pemilihan perumahan di Kabupaten Karanganyar, diperoleh data dalam persentase yang tertera pada Tabel 1.

Tabel 1. Pembobotan Akhir Hasil Perhitungan

\begin{tabular}{|c|c|c|}
\hline FAKTOR PEMILIHAN PERUMAHAN & \multicolumn{2}{|c|}{ Bobot } \\
\hline \multicolumn{3}{|l|}{ 1. PERSEPSI HARGA } \\
\hline 1. Harga & $33,99 \%$ & \multirow{4}{*}{$12,01 \%$} \\
\hline 2. Angsuran & $31,51 \%$ & \\
\hline 3. Uang Muka & $21,16 \%$ & \\
\hline 4. Persyaratan Memperoleh Kredit Rumah & $13,34 \%$ & \\
\hline \multicolumn{3}{|l|}{ 2. LOKASI } \\
\hline 1. Terjangkau oleh Transportasi Umum & $8,59 \%$ & \multirow{4}{*}{$22,96 \%$} \\
\hline 2. Dekat dengan Pusat CBD (Central Business District) & $20,83 \%$ & \\
\hline $\begin{array}{l}\text { 3. Insfrastruktur Jalan yang Memadai } \\
\text { 4. Fasilitas Umum (Kesehatan, Pendidikan, Olahraga, dan } \\
\text { Rekreasi) }\end{array}$ & $31,93 \%$ & \\
\hline 5. Fasilitas Peribadatan & $19,69 \%$ & \\
\hline \multicolumn{3}{|l|}{ 3. KEAMANAN DAN KENYAMANAN } \\
\hline 1. Aman dari Kriminalitas & $45,21 \%$ & \multirow{4}{*}{$29,69 \%$} \\
\hline 2. Aman dari Investasi & $9,28 \%$ & \\
\hline 3. Tingkat Polusi & $25,67 \%$ & \\
\hline 4. Kualitas Bangunan & $19,85 \%$ & \\
\hline \multicolumn{3}{|l|}{ 4. KELENGKAPAN RUMAH } \\
\hline 1. Jaringan Air Bersih & $28,98 \%$ & \multirow{5}{*}{$15,06 \%$} \\
\hline 2. Jaringan Listrik & $24,24 \%$ & \\
\hline 3. Drainase & $18,73 \%$ & \\
\hline 4. Persampahan & $14,53 \%$ & \\
\hline 5. Ruang Terbuka Hijau (RTH) & $13,52 \%$ & \\
\hline \multicolumn{3}{|l|}{ 5. LEGALITAS } \\
\hline 1. Ijin Mendirikan Bangunan (IMB) & $39,03 \%$ & \multirow[t]{2}{*}{$20,28 \%$} \\
\hline 2. Sertifikat Tanah & $60,97 \%$ & \\
\hline
\end{tabular}

Berdasarkan hasil penelitian yang ditampilkan pada Tabel 1, faktor utama yang memiliki bobot nilai terbesar adalah faktor keamanan dan kenyamanan dengan persentase sebesar 29,69\%. Secara garis besar, dapat digambarkan dengan grafik pada Gambar 1. 


\title{
Bobot Nilai Faktor Utama
}
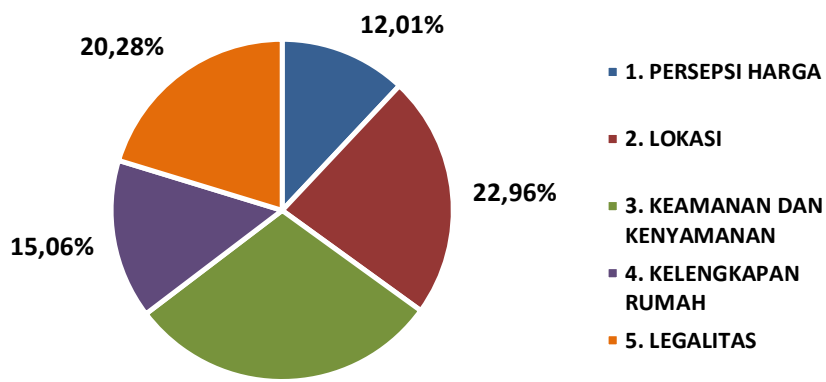

$29,69 \%$

Gambar 1. Bobot Nilai Faktor Utama

\section{Bobot Nilai Faktor Persepsi Harga}

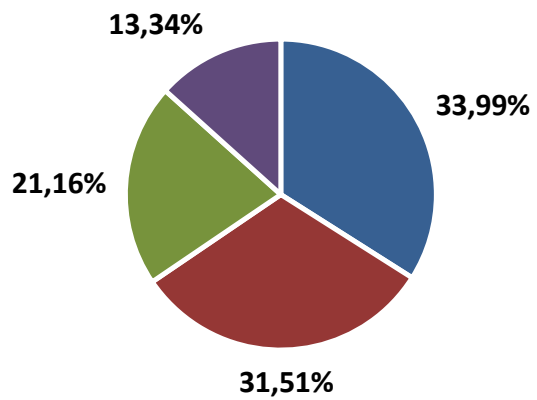

\author{
- 1. Harga \\ 2. Angsuran \\ - 3. Uang Muka \\ - 4. Persyaratan \\ Memperoleh Kredit \\ Rumah
}

Gambar 2. Bobot Nilai Faktor Persepsi Harga

Berdasarkan grafik pada Gambar 2 di atas, dapat dilihat bahwa pada faktor persepsi harga, subfaktor dengan bobot nilai terbesar yaitu subfaktor harga sebesar 33,99\%. Dari hasil tersebut, subfaktor harga memiliki pengaruh terbesar terhadap faktor persepsi harga yang dipertimbangkan masyarakat dalam memilih memilih sebuah perumahan.

\section{Bobot Nilai Faktor Lokasi}

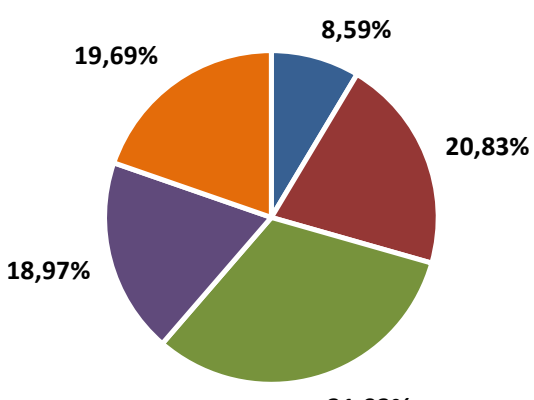

$$
\begin{aligned}
& \text { 1. Terjangkau oleh } \\
& \text { Transportasi Umum } \\
& \text { 2. Dekat dengan Pusat } \\
& \text { CBD (Central Business } \\
& \text { District) } \\
& \text { 3. Insfrastruktur Jalan } \\
& \text { yang Memadai } \\
& \text { 4. Fasilitas Umum } \\
& \text { (Kesehatan, Pendidikan, } \\
& \text { Olahraga, dan Rekreasi) } \\
& \text { 5. Fasilitas Peribadatan }
\end{aligned}
$$

Gambar 3. Bobot Nilai Faktor Lokasi

Berdasarkan grafik pada Gambar 3 di atas, dapat dilihat bahwa pada faktor lokasi, subfaktor dengan bobot nilai terbesar yaitu subfaktor infrastruktur jalan yang memadai sebesar 31,93\%. Dari hasil tersebut, subfaktor infrastruktur jalan yang memadai memiliki pengaruh terbesar terhadap faktor lokasi yang dipertimbangkan masyarakat dalam memilih sebuah perumahan. 


\section{Bobot Nilai Faktor Keamanan dan \\ Kenyamanan}

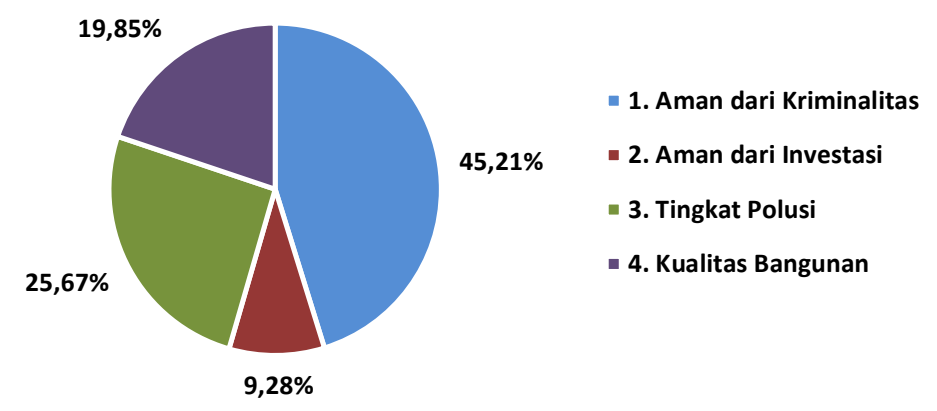

Gambar 4. Bobot Nilai Faktor Keamanan dan Kenyamanan

Berdasarkan grafik pada Gambar 4 di atas, dapat dilihat bahwa pada faktor keamanan dan kenyamanan, subfaktor dengan bobot nilai terbesar yaitu subfaktor aman dari kriminalitas sebesar 45,21\%. Dari hasil tersebut, subfaktor aman dari kriminalitas memiliki pengaruh terbesar terhadap faktor kemananan dan kenyamanan yang dipertimbangkan masyarakat dalam memilih sebuah perumahan.

\section{Bobot Nilai Faktor Kelengkapan Perumahan}

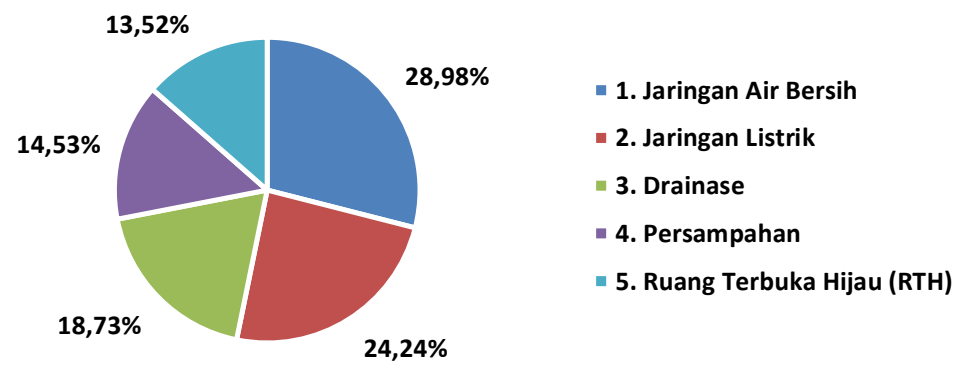

Gambar 5. Bobot Nilai Faktor Kelengkapan Rumah

Berdasarkan grafik pada Gambar 5 di atas, dapat dilihat bahwa pada faktor kelengkapan rumah, subfaktor dengan bobot nilai terbesar yaitu subfaktor kelengkapan perumahan sebesar 28,98\%. Dari hasil tersebut, subfaktor kelengkapan perumahan memiliki pengaruh terbesar terhadap faktor kelengkapan perumahan yang dipertimbangkan masyarakat dalam memilih sebuah perumahan. 


\section{Bobot Nilai Faktor Legalitas}

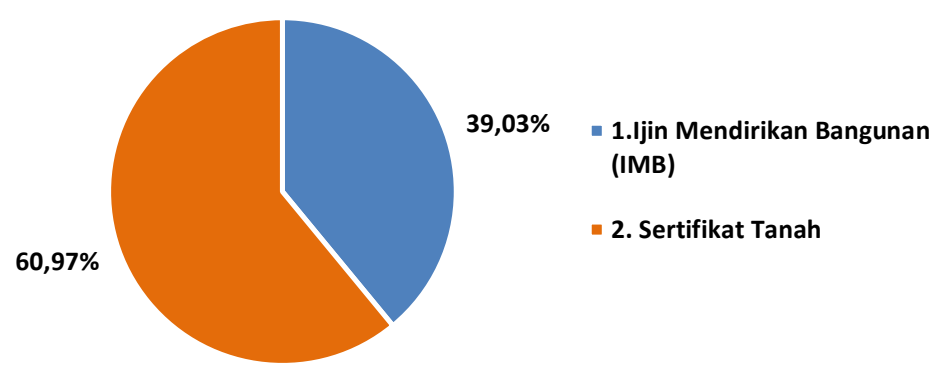

Gambar 6. Bobot Nilai Faktor Legalitas

Berdasarkan grafik pada Gambar 5 di atas, dapat dilihat bahwa pada faktor legalitas, subfaktor ijin mendirikan bangunan (IMB) memiliki nilai yang lebih besar dari subfaktor sertifikat tanah. Subfaktor ijin mendirikan bangunan memiliki bobot nilai 60,97\% dan subfaktor sertifikat tanah memiliki bobot nilai 39,03\%. Dari hasil tersebut, subfaktor ijin mendirikan bangunan memiliki pengaruh lebih besar terhadap faktor legalitas yang dibandingkan subfaktor sertifkat tanah yang dipertimbangkan masyarakat dalam memilih sebuah perumahan.

\section{SIMPULAN}

Berdasarkan hasil perhitungan kuisioner dengan menghitung semua persentase faktor utama, faktor terbesar yang mempengaruhi masyarakat dalam pemilihan perumahan di Kabupaten Karangayar adalah aman dari kriminalitas. Hal ini menunjukkan bahwa, keamanan lebih diutamakan dan dianggap sangat penting dalam pemilihan perumahan.

\section{UCAPAN TERIMAKASIH}

Penyusun mengucapkan banyak terima kasih kepada yang terhormat Bapak Setiono, S.T., M.Sc. dan Bapak Ir. Sugiyarto, M.T., selaku Dosen Pembimbing skripsi yang telah memberikan waktu, pikiran, dan tenaga dalam membimbing penyusun dengan penuh kesabaran, sehingga penyususn dapat menyelesaikan penyusunan skripsi ini dengan baik. Tidak lupa penyusun juga mengucapkan terimakasih kepada seluruh pihak yang baik secara langsung maupun tidak langsung turut membantu dalam penyusunan laporan skripsi ini.

\section{REFERENSI}

Davis, Sam. 1977. The Form of Housing, V an Nostrand Reinhold, New York.

Direktorat Jenderal Cipta Karya. 1992. Perumahan dan Permukiman No.4/KPTS/1992. Jakarta:Departemen Pekerjaan Umum

Direktorat Jenderal Penataan Ruang. 2007. Pedoman Kriteria Teknis Kawasan Budidaya Peraturan Menteri Pekerjaan Umum No. 41/PRT/M/2007. Jakarta:Departemen Pekerjaan Umum

Goodall. 1972. Grub: The Bush Baby. Boston : Houghton Mifflin

Johan, Silas. 1985. Perumahan dan Permukiman (Buku 1 dan 2). Surabaya : Jurusan Arsitektur, FTSP-ITS.

Keputusan Menteri Pekerjaan Umum. 1986. Pedoman Teknik Pembangunan Perumahan Sederbana Tidak Bersusun Nomor 20/KPTS/M/1986. Jakarta:Departemen Pekerjaan Umum

Komaruddin. 1997. Menelusuri Pembangunan Perumahan dan Permukiman. Jakarta: Yayasan REI - PT Rakasindo.

Komaruddin. 1997. Menelusuri Pembangunan Perumahan dan Permukiman. Jakarta : Yayasan REI - PT. Rakasindo

Luhst, K. M. 1997. Real Estate Evaluation. USA: , Principles Aplication Press.

Mardhikawarih, D.A. 2012. Pemilihan Pemasok Drum Pelumas Industri Menggunakan Fuzsy Analytical Hierarchy Process. Surakarta : Program Studi Teknik Industri Fakultas Teknik Universitas Sebelas Maret 
Qathafi, Mu'ammar. 2012. Preferensi Masyarakat di Kota Ponorogo dalam Memilib Perumahan dengan Menggunakan Metode AHP (Analytical Hierarchy Process). Surakarta : Program Studi Teknik Sipil Fakultas Teknik Universitas Sebelas Maret

Saaty, T L. 1994. Pengambilan Keputusan Bagi Para Pemimpin, Proses Hierarki Analitik untuk Pengambilan Keputusan dalam Situasi yang Kompleks. Penerjemah : Peniwati K. Jakarta: Pustaka Binaman Presindo.

Turban. 2005. Decision Support Systems and Intelligent Systems (Sistem pendukung keputusan dan system cerdas) Jilid 1, Andi Offset.

Wonosuprojo, S. Risyanto, B R. Budi, S. 1993. Kesesuaian Lahan untuk Pemukiman di Kecamatan Galur dan Kecamatan Lendah di Dati II Kulon Progo Propinsi DIY. Yogyakarta : Fakultas Geografi Universitas Gajah Mada 